\title{
ON FAITH, POLITICS, PRIVILEGE, AND OTHER DEMONS An interview with the novelist Christos Tsiolkas
}

\author{
Daryll Delgado \\ darylljsd@gmail.com
}

\begin{abstract}
About the Interviewer
Daryll Delgado's first novel, Remains, is forthcoming from the Ateneo de Naga University Press. Her first book of short stories, After the Body Displaces Water (USTPH, 2012), won the 32nd Manila Critics Circle/National Book Award for best book of short fiction in English, and was a finalist in the 2013 Madrigal-Gonzales First Book Award. She received a Philippines Free Press award for her fiction in 2010. She has taught at UP (Tacloban College), Ateneo de Manila University, and Miriam College. She works for an international labor and human rights NGO, and writes global reports on labor rights issues. She resides in Quezon City with her husband, William. She was born and raised in Tacloban City, which she continues to call home.
\end{abstract}


The notion that the author, the writing process, and the intent behind the text are irrelevant, as per John Barthes's essay, "The Death of the Author" (1967), is difficult to apply when dealing with the works of novelist Christos Tsiolkas, one of the most prominent literary figures from Australia today. Christos, of Greek descent, and whose background is Political Science (from the University of Melbourne), is highly articulate and generous (and self-deprecating) not only when discussing his own work and their historical and social context; but his creative process and its intersection with his politics as well. One comes away from a conversation with Christos, who describes himself as "Someone from the Left," usually challenged, illuminated, even transformed. And always reminded of the labor cost and material consequences of writing.

Christos Tsiolkas is a critic, essayist, playwright, and screenwriter. He has five critically-acclaimed and awarded novels to his name: Loaded (1995), which was made into the feature film Head-On in 1998; The Jesus Man (1998) and Dead Europe (2005), which were awarded the 2006 Age Fiction Prize and the 2006 Melbourne Best Writing Award; The Slap (2008), for which he won Overall Best Book in the Commonwealth Writers' Prize 2009, Australian Literary Society Gold Medal, and the 2009 Australian Booksellers Association and Australian Book Industry Awards Books of the Year, was longlisted for the 2010 Man Booker Prize, and shortlisted for the 2009 Miles Franklin Literary Award; and Barracuda, published to rave reviews in late 2013, a bestseller, and which, like The Slap, was adapted to television and shown on HBO internationally. A collection of short stories, Merciless Gods, released in 2014, and recently adapted for the stage, has likewise received critical praise. Cassie Tongue, in The Guardian, writes, "Tsiolkas's collection stared down the dark corners of our hearts and the dark corners of our cities, and found irrefutable humanity there: in visiting old Australian migrant camps; in saunas and grubby flats; in the arms of an abusive lover; in truckies who arm themselves against 'the blacks'; in a dying parent; in an unhappy marriage with a racist; in the gulf between a socialist radical and his conservative brother. It's not so much cultural cringe as it is cultural reckoning, exposing darkness in ourselves and working to temper that darkness with empathy." In 2018, Christos Tsiolkas on Patrick White, was published as part of the Writers on Writers series of Black Inc. Here, Christos ruminates on the life and works of the Nobel prize winner Australian writer, Patrick White. The book bears all the marks of a Tsiolkas work - provocative, searing, sensitive, and sufficiently controversial. His latest novel, Damascus, which he has described as being about Saint Paul and the question of faith, is coming out in 2019, and already creating a buzz.

Words like "shocking," "brutal," "graphic," "violent," "savage," "angry," alongside such contradicting terms as "tender," "humanizing," "brave," "decent," "poetic," and "joyful" have been used to describe a single Tsiolkas work. The author himself,

Kritika Kultura 33/34 (2019/2020): 915-929

(C) Ateneo de Manila University

<http://journals.ateneo.edu/ojs/kk/> 
outside of his books, is outspoken about class, ethnic divides, gender inequality, and politics, in general. He eschews social media, however, saying that he can be very hotheaded on politics, and worries he will get into fights. It is a good thing that he has a monthly column on films in The Saturday, and a weekly music radio program to turn to when one is simply hungry to know what colorful things Christos has to say about the goings-on in the world. His interviews, such as this one in The Garrett where he gives a nice shout out to Philippine writing and his visit to the country (https://thegarretpodcast.com/christos-tsiolkas-live/) and $B B C$ Hard Talk (http://www.bbc.co.uk/programmes/booz8f6c), and even his parts in the radio show "Superfluity," are a joy to listen to because of the lucidity of his subject position and the openhandedness and humility with which he explains it.

In late January 2017, Tsiolkas was in the Philippines as part of the Writers Immersion and Cultural Exchange (WrICE) program, and it was here that he openly discussed Damascus, then a work in progress, and provided feedback to the other writers in the program. During a fiction-writing workshop in one of the universities in Manila, Christos talked extensively about his work process, the mistakes he has made, and his struggles as a writer, to an intimate audience composed of students and teachers.

In Melbourne, for the second leg of the WrICE residency, while walking around Fitzroy, he gamely shared with us, visitors to his hometown, personal knowledge, and significant and embarrassing experiences, associated with old buildings and street corners. He pointed out structures, which used to be factories-laughingly saying that his mother instructed him to remind his visiting friends that the place was built on the blood, sweat, and tears of migrants. He pointed out the statue of an Australian Prime Minister whom he most admires, and tied it to a memory of his dad taking him to his first street protest. Coming into the business district, we walked right into a massive equality rally, which he said he did not even know of. He shared that while he fully supports the bid for marriage equality, he believes there are other issues intersecting with this one that need to be problematized as well. He remains wary of knee-jerk reactions and trite political statements, selfrighteousness and stock political correctness. As he said in the On Revolution panel at the Melbourne Writers Festival, "I still hate censorship and Puritanism, whether the censors be from the Right or from the Left. I still wish there were no such thing as private schools or religious schools... I still want to be astonished, by a painting, a poem, a film, a piece of music, by the revelations and laughter between friends in the early hours of the morning. And if I can't dance, I still don't want to be part of your revolution."

The time I spent with Christos Tsiolkas in the Philippines and in Australia, thanks to the WriCE program of RMIT, provided me and the other writers in the 
program, many occasions to not only seek his advice about writing and political engagement, but also about family and relationships, art and music, films and food, which easily find their way into the conversation. This interview started in April 2017, over email, and makes references to in-person conversations that happened in late August to early September in Australia. It was then followed up by another round of email exchanges in November 2018.

Daryll Delgado: Congratulations, on the YeS vote, and passage of the bill. This brings back lovely memories of that day we walked into the equality rally in Melbourne, and what you said about other intersecting issues that you feel need to be tackled as well. How does the vote make you feel? Does knowing that you live in a country that largely supports equality - at least in the legal right to marry - make a difference to you as a writer, and as a gay person?

Christos Tsiolkas: That is indeed a lovely memory, our walk together into town as the rainbow colours spilled out on the streets.

I think that the YES vote came as a huge relief, that the overwhelming support for same-sex marriage meant that it indicated a certain shift and change in Australian culture regarding sexuality and LGBT culture. My partner, Wayne, described it, as the move from "tolerance to acceptance" and that seems right. I think the relief also came from the sense that maybe the general culture is braver than the political culture, that whereas our politicians had run away or been terrified of the issue of same-sex marriage for a decade, the general population proved itself more intelligent and more progressive than the politicians.

So yes, relief. But for me, personally, the fact of same-sex marriage doesn't change anything in my immediate life. Wayne and I have been together for over thirty years and forging the love and commitment we have has been in part communicating with our families about the meaning and the sincerity of that love. I think that work within families and communities - of bringing one's love and sexuality out of the shadows - is particularly important for queer people whose backgrounds are immigrant and/or refugee, or whose families don't have the access to the language of diversity and liberalism that is part of the bourgeois Australian culture. To use my own example, I have had to translate the meaning of my love and sexuality to my parents, having in part to create a new language to express it because I didn't know how to communicate it effectively in Greek and my parents could not speak or comprehend English very well. And in fact, it wasn't merely a matter of direct translation. Their Greek- rural, working-class, communal, almost pre-modern 
- and my English - educated, then increasingly bourgeois as I entered university meant that we had to work very hard to find new ways of speaking about something that was for so long unspoken and not allowed to be spoken. That we did says much of the grace and patience and courage of my parents. It was difficult for them, very difficult. They had to survive the shame that came from learning such a language. But their love for their son proved stronger. I am so grateful for that.

What does all this have to do with the YES vote? It is a relief, and within our legal and political institutions, it gives us queers a security and an acknowledgement as citizens that are crucial and fundamental to our feeling equal as citizens within Australian democracy. But our sexual and love lives have to be negotiated within complex familial, personal, religious, linguistic, and cultural ties as well. So, I guess I'm saying that for my mother and father to accept me as a gay man, to accept my lover, given the world and class and background they came from, is what matters most to me. It is not either/or. I am very thankful we as a nation voted YES. But my family's acceptance meant so much more to me than the state's acceptance.

What does all this have to do with writing? I think that in trying to create a language to communicate myself to my parents (and in turn, listening to the language they created to communicate themselves to me) has been deeply significant for my writing. I suspect that all writing is in part a matter of translation, of how we make sense of ourselves to each other.

DD: In an interview (The Guardian, November 2013), you mention that one thing that makes you angry is "self-righteousness," and you elaborate on this in another essay on the politics of rage. I see that variations on this theme appear in your books. How important is it to you and to your writing to expose the self-righteousness that underscores individual and collective action? Is this something that drives your work?

CT: I think for me what is powerful about fiction is that it allows for complexity and for ambiguity. And for fiction writers to be true to their imagination and to the characters they create, they need very much to have a sense of charity when it comes to the worlds they are creating. That doesn't mean that a writer isn't able to have critical distance from their characters nor that as a writer you can't make judgments - ethical, political and moral - about your characters, but judgment is not the same thing as being judgmental. I think there is something brutal and cruel in self-righteousness precisely because it refuses ambiguity and contradiction. 
Though it has been a long time since I had religious faith, I think maybe one of the gifts that Christianity gave me was the notion that none of us are without sin. I remember from a very early age being struck by the strong ethical truth of that Christian injunction: that none of us have the right to throw the first stone. It means that sometimes I can be an ineffective political activist; sometimes politics demands surety and directness. But fiction, never. Fiction that wants to throw the first stone is-for me-always failed fiction.

DD: Thank you for this! I completely agree. But, do you subscribe to the notion that part of the work that we do as writers is to go against the grain, to expose other ways of viewing reality and the things going on around us? I know you said that you don't always consciously think of readership, but do you think that people, or at least [your] readers, have become a more mature lot, politically, and is this something that you feel you have to address/cater to in your writing?

CT: It may be part of becoming middle-aged, but I am becoming increasingly conscious of how there are now new generations of writers and critics, and that they are developing new forms of language and thinking that I am not privy to. There is a sense I have that it is only right that these new generations speak and that of course these emerging voices and writers might want to throw stones and sticks at my generation, myself included, for the mistakes and evasions that we, perhaps unknowingly, committed in our own practice.

I think it would be a mistake to try and "keep up" with politics as a writer. At some point, you have to realize that time does play a role in the work we do, as it does in all labour. There is an ethics that is central to how I live my life, an ethics that, of course, informs the way I write and what I write about. This ethic was formed over time, challenged and amended by personal and political experiences. I must, on some level, assume that my "perfect reader" shares in that ethic. Not that they think exactly the same way, but that the direction of our beliefs, our politics, of the questions we wish to pose, is akin. I think this is the reader I want to challenge most with my writing. That is to say, I want to challenge someone like myself. I want to challenge the censoriousness and smugness of my left-wing surety, the privilege of my inner-city urban cosmopolitanism, the tendency to moral selfregard and intellectual vanity that is too often part of the artistic, academic, and literary worlds.

DD: That's a brave and, I think, really necessary, statement to make. It is all too easy to fall back on the sense of certainty that we have acquired from our privileged 
positions. But what makes us different from the powers we contested, indeed, if we do not allow a more engaged and rigorous questioning? Thanks for that. If selfrighteousness makes you angry, what is it that moves you and inspires you, these days? And what is it that scares or concerns you the most, as a writer?

CT: I am inspired by the dedication of people to their craft, to their work, to their loved ones. It might be simply a function of my turning fifty last year and so being very aware of age; for whatever reason, I respect people's dedication to the work they do. I lost my father four years ago and I recognise that for my father, his garden was his work, his art. He grew up in a peasant family, a life on the land, and then, because of the political situation in Greece, he migrated to Australia and worked in cities, in factories, for most of his adult life. But he never forgot the love of land, and the small suburban garden he created was something he nourished and grew with real love. I think it's no accident that my partner, Wayne, is also a wonderful gardener and the garden he has created for us is his passion. This kind of dedication is always inspiring.

Generosity, too, that is always inspiring. I have been very fortunate to have found generosity from writers in my life-the people who have mentored me, instructed me, and took time to tutor me. I think that the spirit of generosity is very important and needs to be cultivated more by writers and artists, to counter the competition and ego that is so much part of the arts world. That's not to say that I've managed to conquer ego and envy. Far from it. But that's what I want to aim for: to try and be more generous in the communities I live and work in.

I get scared that the great education reforms that were so essential to so many places in the world in the twentieth century are no longer seen as urgent and important as they once were. Knowing what a gift education is, and also knowing people within my own family that were denied the right to education, makes me want to defend education as much as I can, in particular public education. In Australia, there is an increasing disparity in the education system and that deeply saddens me. I think it's crucial that writers and artists defend the importance of pubic and universal education.

DD: Education-access to it, the effects of it and the dramatic context of it-is indeed one of the most memorable themes in your work. Coming from my own context, a developing country where the quality of/access to education is always one of the most visible indicators of inequality, your treatment of it is something that I find deeply moving, because, of course, it is bound up with the issues of class, 
of identity, of belonging, and of privilege, and the nature/source/consequence of privilege.

But what is your own notion of privilege? What, at this point, do you think are privileges you've acquired? How do these affect you, your writing? I know you've also talked about complacency, and how you've been trying to fight it. Thank you, by the way, for that. I find it very refreshing to listen to someone who has accomplished so much in his/her field speak of these things with such candor.

CT: My sense of privilege was soldered onto me from the very beginning of my falling in love with literature, with reading, simply because I was able to read. This access to education, an access that my parents did not have, meant that I knew I was fortunate. That I had been given the opportunity to have something momentous that was denied to many people on the planet. My father, my mother, would not have migrated if they had been educated. They would have stayed in the country they loved, been surrounded by the language they spoke. I had been given from the outset an opportunity that was denied to them. This knowledge, this understanding, is the central underpinning of my ethics and responsibilities when it comes to understanding myself as a writer. That privilege is an opportunity and great fortune and that it is ALWAYS determined by the labour, the sweat, the sacrifice, the exploitation of others. My mother's wrists were twisted and maimed by the factory assembly lines. My father's back was destroyed by his labours. That is how my education and my literary success were financed. I don't mean this to be melodramatic. It is the truth. And from what I gleaned as child and an adolescent and then an adult, as I realized the nature of my parents' labours and sacrifices, I, of course, came to understand that this is how privilege works in the world generally.

So how do I feel about my privilege? That I am so very fucking fortunate. That if I were ever to believe such fortune is my due or my right then I know I have become a failed human being and a failed writer. Please don't misunderstand me. I'm not advocating some masochistic self-flagellation - "Oh woe is me, look how privileged I am": this insincere masochism is what I deplore most in both Christianity and left-wing politics generally. What I mean is that I try and take this understanding into the language I use, the stories I write. It was interesting with the release of Merciless Gods, because some of those stories are over twenty years old, from a time before "success." There is a story in that collection, "Porn 2," that I don't know if I could write now. I wrote that in the voice of an underclass young boy. I knew that voice, or I was closer to it, twenty years ago. I'd feel a little false writing in that precise voice now. But I don't think this means refusing to write in another kind of voice that acknowledges the reality and pain and beauty of such a character. Too often these days, writers use the sense of their "privilege" - whether they are 
referring to race, ethnicity, colonialism, nation, gender, sexuality - to argue that they can't write about certain subjects or use certain languages. It means that our literary cultures are in the danger of becoming increasingly insular and irrelevant.

This is not an easy question. I think I will be grappling with this question, as a writer and as a human being, till the end of my life. I know I will. Maybe one of the best things I can do in terms of acknowledging "my privilege" is to shut up from time to time, to listen to the voices that I haven't heard before.

DD: Speaking of education, and privilege, in writing Barracuda, was it clear to you right from the start what the novel was going to be about and where it was going to be headed, not just in terms of plot, but also in terms of the big themes?

CT: I have described the writing of Barracuda as a series of small streams that all ran into one river to form a giant torrent. What I did know was that I wanted it to be about class. Barracuda was the first novel I wrote after The Slap, which was a big success. I am very grateful for that success, including that it gave Wayne and I financial security for the first time in our life. But with that security came the understanding - I had always known this - of how much class does matter. That was certainly one of the dominant things I wanted to explore in Barracuda. But also, of course, the question of what success and failure mean. That is why I wanted to write about sports, because in sports, there is a certainty to achievement that is just not possible in writing and in the arts. The swimmer who swims the fastest time is clearly the winner. But as a writer, no matter what success and no matter what awards, there is always that inner voice of doubt that whispers: You don't deserve this. I'm sure every artist in the world has to learn how to battle and find peace with that voice.

Barracuda, in a strange way, felt like writing a first novel again. Through the character of Danny Kelly I was also reflecting on myself as a young man. But, because I was in my late forties when I started writing the book, I could look onto the character with a tenderness and a care that maybe I couldn't have offered him twenty years ago. That tenderness was very important to me in the writing of that book. It comes back, Daryll, to my concerns about self-righteousness and judgmental thinking. We can be very tough on young people, sometimes very cruel. I wanted to write a story against that cruelty. Danny does some awful things, and I really wanted a reader to understand Danny's shame. But, I think he [Danny] makes genuine atonement. That is what self-righteousness precludes-the opportunity for atonement. That was one of the strongest themes for me, the notion of shame 
and making atonement. It's not that I knew that clearly from the start of the novel but in the writing of it, that theme, that "stream" became dominant.

DD: I think it's beautiful, and inspiring, how you describe it, the way themes emerge in the writing. You've mentioned that you had multiple versions of Barracuda before deciding on the final one. I think the narrative structure is as much the story, in this novel as in Dead Europe, in Loaded. And thank you so much for that, what a gift to the reader's imagination, these movements and shifts. How did you arrive at that decision, to structure the novel in that way? This is something that the miniseries adaptation of the novel does not follow, although the story comes through beautifully in this medium too.

CT: I never studied creative writing, so in a way, I discovered how to write a novel in the process of actually writing. With Loaded, I first had the voice of Ari, the main character. But, I couldn't quite work out how to structure the story of this young man. And then I remember, sitting over the typewriter, and thinking, why don't I set the novel over a 24-hour frame. It was a simple instinctive response but it allowed me to start thinking of the story as a novel, with a defined structure.

That searching for a structure and a framework for the narrative I am telling is very important in my thinking through of how a novel works. In Dead Europe there are alternate chapters: the historical past written in a savage folkloric style (I owe this voice to my parents), almost magical, and then the more contemporary voice of the photographer Isaac. My hope in that novel was to eventually blur the two different modes of writing, so that by the end, Isaac is trapped in the brutal folkloric past. It was a way of my trying to get to how history gets us all in the end, how impossible it is to outrun the obligations and terrors of history.

In Barracuda, I wanted the reader to know from the beginning that Danny Kelly never got an opportunity for Olympic glory. I wanted to indicate to the reader that the novel was about something else: both success and failure, shame and forgiveness. In the writing of the book, I also realised that the structure I chose gave me an opportunity to trust the reader to fill in the blanks. I mean by that, that in having one voice going chronologically forward and one going chronologically backward, I was free to concentrate on the events and emotions and experiences of Danny Kelly that were most important for him. A real clear example of that, Daryll, is that I knew Danny was gay - I knew that from the very start - but I also knew I didn't want to write a "coming out" story. This is what I mean about trusting the reader, trusting that the reader have their own imagination and history and they 
don't need to have every thing spelt out. We never see the moments when Danny comes out to his mother and his father, his family. We fill in the gaps ourselves as readers. That was my hope. It was incredibly liberating to have that structure, to know that I didn't have to underline everything.

DD: I think it was also liberating for me, as a reader, to be given the opportunity to fill in the gaps, or rather to unstick the parts of the novel that would have dealt with Danny's coming out. As a young writer, were there specific books that dealt with sexuality and politics that inspired you, or at least made you want to interrogate the subject?

CT: I was knocked out as a young reader by Ralph Ellison's Invisible Man. There was something in that novel that spoke to me about the almost impossible task of translating oneself in a culture over-determined by racism and class. Ellison's Invisible Man is African-American, he is not gay, so how did I read myself in him? Because Ellison made me understand that the task of translation was to be mine, and that I was going to have to write myself to make sense of myself. I mention Invisible Man because I don't think that inspiration is necessarily that straightforward. There were of course books like James Baldwin's Giovanni's Room, Jean Genet's The Thieves Journal and John Rechy The Sexual Outlaw that were formative and thrilling in allowing me to imagine writing homosexuality and desire, but Norman Mailer and Henry Miller's work was equally as important for that. Also, a book like Carson McCuller's The Heart is a Lonely Hunter was pivotal. I love that book, of how it seemed to speak to me across geography and time, to give voice to a loneliness and an ache that I thought was only mine to bear when I was an adolescent. One day I must visit her grave. To give her my thanks.

DD: Speaking of books that reach across geography and time... After The Slap, did you immediately start on Barracuda? Were you concerned about the reception to Barracuda, after the huge success that met The Slap?

CT: I'd be a liar if I pretended otherwise. The success of The Slap was wonderful, but it also was distracting, because for a period I didn't know for whom I was writing. Previously to The Slap, I knew I was writing for myself. I needed to get these stories out of me, I needed to wrestle with demons and make my peace. But, for a period after The Slap, I would vacillate between two different choices. One was being able to write The Slap2 and the other was to write something so deliberately ugly and unreadable that it would spit in the face of my success. I realised that both those options were the wrong ones, and that both would be destructive for me as a writer. 
I think this is where the importance of my love for Wayne carried me through. We've been together since we were both 19 and he knows how important writing is for me; he has been unstinting in his support. He just kept saying, Take your time, take your time. And that was exactly the right advice. I took my time and suddenly, I woke up one morning and I had a voice in my head. Of young Danny Kelly. And I knew I could begin again. I think that's why I say that Barracuda is like writing a first novel. I had to learn how to ignore the white noise of success - and the fear of failure - and go back to the basics.

DD: Your novels are hugely about and, I think, deliberately, different subject matters, and are indeed remarkably distinct from each other - in structure, in pace, in "color" and in texture. As in, literally, moving from one book to the other, I sometimes see different color palettes at work. Was this something you were conscious about?

CT: Daryll, to be honest, it's not that I am conscious of how different they are thematically. In a sense, I think there are certain themes that come up again and again in my writing. Faith, both political and religious faith; family; migration; shame. So, for me, there is continuity in the novels. But, I do love the element of "play" in what we do, of taking risks, of trying out new brushstrokes and new colours, to extend the painterly metaphor. I think this is where we are most fortunate to be writers, this element of "play".

DD: But, yes, there are obviously common threads, not just the race-class-gender discourse or the politics that define identities and selves, but also those that bind people together -- friendships and sexual relationships, families and histories, education and learning, music, food, alcohol. Why are these themes and/or elements important to you? How have these themes shaped you?

$\mathrm{CT}$ : There is a quote that I use at the beginning of Loaded by the Mexican-American writer, Richard Rodriguez, where he refers to the responsibility the child of migrants feels to their parents, to their struggle and sadness ("for there is always sadness in migration, the loss of home, of family, of language"). I feel this responsibility acutely, how much I owe my mother and father for their sacrifices. And also for their beauty.

It's a story I often tell but, when I was very young, still in elementary school, Dad was so proud that I read. Because of World War II and then the Civil War in Greece, he never had the opportunity for an education. Every Thursday, which 
was payday at the factory he worked in, he would walk home past a bookshop and buy me two books. As he couldn't read English, sometimes he'd buy me Dickens, sometimes some highly inappropriate sex book. I remember he bought me Henry Miller once - I must have been nine years old! I am very glad for that uncensored literary education.

In a way, it was even harder for my mother. She had some elementary education but it was inconceivable to imagine girls getting an education in the villages back then, so she started work very young. Knowing the toughness of their history, knowing the hardness of their lives, knowing their deep love for their children and family, I was - as I said - so very aware of my responsibilities to their sacrifices. But, at the same time, I was also aware that I needed to strike out on my own, be my own person, defend my sexuality, my desire to be a writer, all things that were threatening and almost alien to my family. That in-betweenness-caught between responsibility and the desire for independence-that is the central theme I have been picking at, working at, and trying to understand in my writing. That is why family is so central to all the books. My books, in some ways, are a conversation I am having with my family, trying to explain my strange world to them. And in doing so, explaining it to myself.

DD: In Dead Europe, a book filled with very intense, tension-filled images, the images of tenderness, rest, and cessation of activities seem imbued with just as much importance and value. How important is the notion of rest to you - as a narrative device, as a metaphor, as a political act? Many, many things about this book that I love. This is one of those books that are a gift to teachers of literature and creative writing, because it's very instructive - themes-wise and techniquewise. I would have included this in my list if I were still teaching. But, yes, I was very struck by the quiet scenes like when Sal Mineo lies next to Isaac to soothe and comfort him, and in the same chapter-The Brothel of Prague-Isaac does this to his friend too.

$\mathrm{CT}$ : That's a really perceptive comment. There is so much brutality in Dead Europe but for me the important moments are the ones of tenderness. It's what my own search is, to find a way of being at rest and at peace. I think this is so important for all of us and so very hard to do in the world we live in. I used to have access to such moments of rest and peace when I was religious. But with the loss of faith, learning how to find those moments has been a struggle. Even though I am no longer a believer in a transcendental God, I still think the questions posed by the great religions are worth asking. What is good? What is evil? What is a good life? Only a moral idiot would think such questions not important. 
Dead Europe was about the death of faith for me, the death of religious faith and also the death of political faith, a faith in something called communism. Even though I have abandoned the faiths, I haven't abandoned the questions and concerns that animated those faiths.

I had a little note that I stuck above my computer while writing Barracuda: "This is a novel about what it means to be a good man."

DD: In what form does rest come to you, when you're at work on a book? How long a break do you allow yourself in between chapters, or in between book projects? Or are you always writing? Is your mind always working on a novel, or a story?

CT: I've always loved a phrase of Doris Lessing, where she refers to "fugging time." That is the time writers seems to be daydreaming but it's actually a really important part of the writing process, that it is during "fugging time" that words, moments, phrases, and ideas come to us.

I love walking. Whole worlds open up for me when I am walking. Walking is my rest. I try and incorporate a long walk into my work every day. Am I always writing? I try to, try and write at least 1500 words a day. Sometimes they're shit, you erase most of them, but I do think it is a way of exercising the muscles of imagination.

DD: Do you work to music? It seems to be a real presence in your work. What music are you working to right now?

CT: Music is certainly a presence, I think of writing musically. I listen to music all the time but not when I am actually physically writing. I find that I disappear into the music and lose my concentration. But the beginning of my day and the end of my day is always scored to music.

I have been listening to a lot of jazz recently. The inventiveness of that form is a constant inspiration. And I have been listening to a lot of gospel music, because the new book is called Damascus and it is about St Paul. It's interesting, I have only just realised it while writing this to you, but I have been listening to jazz and US gospel, two of the great artistic innovations that came out of African-American culture.

DD: What is your writing process for Damascus, the novel you're currently working 
on? Is it similar to how you did your other novels? What has changed for you, routine-wise or process-wise? What accounts for this change?

CT: The main difference between Damascus and my other novels is the time I gave myself to research and read. I had the idea for the novel but forced myself not to write a word until I had spent a year reading theology, history, and philosophy. It was a terrific experience, like being a student again, but a much better student this time because I had a real fire in my belly to try and understand St Paul and the world he lived in. Once I actually began the writing of the novel, it isn't dissimilar to how I have written the others. I am a firm believer in treating our craft as work, putting the hours in. There are geniuses who can write without such discipline but I am certainly not a genius. What I love about writing is the dedication to craft, to the work. It feels like it brings me in communion with my father. He had his garden, whereas as I have my writing.

DD: You've talked about exorcising demons through writing. What is it-if you can share-that you're trying to exorcise in the novel you're working on right now?

CT: For a long time, I felt I was wrestling with Paul, but the last six months I feel like I am walking in step with him. I think I want to exorcise the terrible layers of shame that corrupted my engagement with Christianity, the shame of sexuality, the shame of being an outsider.

DD: Do you always have a sense of an audience, or a readership, when you're working on a book? Who is your imagined reader? Your ideal reader? Is Asia, or Southeast Asia, as an audience, in your ken, in your range of sight/consciousness as a writer?

CT: This is going to sound very selfish, but I don't think of a reader when I am writing. I am writing for myself: for play, to exorcise ghosts, to be exhilarated, to battle with the questions that will not stop assailing me. Is it selfish, to not have a reader in mind?

Though it is true that I don't have a reader in mind when I am writing - I am writing for myself - I have been very fortunate to have always had the same publisher, Jane Palfreyman. Jane is also a terrific editor and she is always the one 
who makes me confront questions to do with readership. Am I making myself clear? Am I forgetting my story? Are my characters realistic? What I trust about my relationship with Jane is that she is committed ultimately to the writing; she is fiercely protective of her writers. But she also makes sure I remember that books come alive in the reading. It is in the editing process that I become aware of the need to communicate as effectively and honestly as I can with my readers. It is not that I necessarily have an "ideal" reader. Rather, a writer has to trust their editor otherwise the relationship is soiled. In that sense, your editor has to be your "ideal" reader. This is why I treasure the long professional relationship I have with Jane.

In terms of the question of an awareness of a Southeast Asian audience, I think that as an Australian writer, my responsibility is to make sure I read as widely as I can, writing that comes from outside the Anglo and European worlds. I can't write as an Asian but I can read Asian work and be inspired, entranced and challenged by it. I think this is crucial, that we Australians challenge ourselves to read beyond the usual limits.

I think what was wondrous about being in the Philippines was realizing that the world is so much larger, more complicated, more difficult, more harsh, and more beautiful than I knew. Every experience-if you are lucky and you are open to itmakes you a better writer. But more importantly, it makes me a more knowledgeable and less parochial person. 